\title{
Behavioral Characteristics Prototypes of Academically Talented Students: Implications for Educational Interventions
}

\author{
Rosadah Abd Majid ${ }^{1}$, Zalizan Mohd Jelas ${ }^{1} \&$ Noriah Mohd Ishak ${ }^{1}$ \\ ${ }^{1}$ Universiti Kebangsaan Malaysia, Malaysia \\ Correspondence: Rosadah Abd Majid, Universiti Kebangsaan Malaysia, Malaysia. E-mail: \\ rosadahm@yahoo.com
}

Received: May 18, 2012 Accepted: August 21, 2012 Online Published: November 30, 2012

doi:10.5539/ass.v8n15p298 URL: http://dx.doi.org/10.5539/ass.v8n15p298

\begin{abstract}
Gifted and talented students must be identified for teachers to be able to help students realize their potential. The Malay version of Renzulli's Scales for Rating the Behavioral Characteristics of Superior Students (SRBCSS) has been used by teachers to rate behavioral characteristics of 33 academically talented students. The data obtained were analyzed by multi-dimensional scaling analysis to yield two prototypes of behavioral characteristics of those students. The first prototype demonstrated high ratings in Dramatic, Artistic, and Musical characteristics. The second prototype showed high ratings in Expressive Communication, Precision Communication, Leadership, Motivation, Learning, Creativity, and Planning characteristics. Academically talented students need appropriate teaching and learning strategies to improve the behavioral characteristics for which they received low ratings.
\end{abstract}

Keywords: gifted, academically talented, rating, behavioral, characteristics, prototype

\section{Introduction}

High-ability students require challenges that match their abilities to reach their full potentials. Teachers must be aware of the presence of these students in their classrooms. Nevertheless, the field of gifted and talented education is not well-defined in the Malaysian system of education. A central tenet of the educational philosophy of the Malaysian education system is to develop every student's potential to the fullest. Though the system has put considerable effort into educating children with special needs, it has not fully acknowledged the needs of gifted students. The goal of some programs for highly able students, who received an "A" in all subjects in which they were tested in the National Primary School Assessment (Ujian Penilaian Sekolah Rendah-UPSR) or in the National Lower Secondary School Assessment (Penilaian Menengah Rendah-PMR), was to enroll them in boarding schools. Only a few teachers in the schools were taught specifically about educational needs of high-ability students.

Many students can be categorized as high-ability, but they are not selected to go to boarding schools. They remain in day schools throughout the country. However, teachers in most schools are not exposed to knowledge about gifted education. Thus, they are not well-equipped to accommodate high-ability students and to develop these students to their fullest potential. There is no procedure for identifying gifted and talented students within the Malaysian system of education. Nevertheless, Piirto (1999) suggested that $15 \%$ of the school population could be gifted and talented, but these students are unrecognized by the system. Giftedness could be within various domains of talents, and academic talent is one of the domains. Academic achievements may indicate that a student is academically talented (Renzulli, 1999). Teachers should be aware of this phenomenon and employ teaching strategies designed to develop the academic potential of these students.

This research was performed to examine behavioral characteristics of students who are academically talented. This is an attempt to understand their behaviors in these ten domains: Learning, Creativity, Motivation, Musical, Planning, Artistic, Expressive Communication, Receptive Communication, Leadership, and Dramatics. Knowing the characteristics of these gifted learners gives us a general idea about their educational needs. Thus, teachers could devise teaching strategies and plan interventions to meet students' needs. In addition, by knowing that certain behaviors are characteristic of gifted learners, adults will not be surprised or disturbed when the learners exhibit some of those behaviors. This will help to minimize conflict among students with their parents or their teachers. The conflict may occur when adults misunderstand or misinterpret certain students' behaviors. A student who is engrossed in completing an invention is considered very motivated and creative, though 
sometimes he may neglect himself. He would skip his own meals for the sake of invention.

\subsection{Understanding the Behavioral Characteristics of Gifted Students}

Gifted students are also referred to as high-ability students. Definitions of gifted students include those children who can produce creative products. These students are not without problems . Their problems include boredom and frustration in school and sometimes isolation (Woolfolk, 1998). They may also find it difficult to accept their own emotions because the mismatch between mind and emotion can be great. Sometimes they get impatient with friends, parents, siblings, or even teachers who do not share their interest or abilities. Gardener (as cited in Woolfolk, 1998) mentioned that a creative student regularly solves problems, fashions products, or defines new questions in a novel way. This is indicative of a divergent thinking pattern. They may have multiple answers to a question, which may sometimes seem ridiculous. Some gifted students are regarded as different and peculiar (Piirto, 1999; Clarck, 1997; Gross, 1993). It is interesting to find out how exactly do the behaviors differ comparing the academically talented with their typical counterpart.

Certain distinguishable behavioral characteristics have been associated with gifted and talented students. Inderbir (2001) listed nine observable behavioral characteristics of a group of Malaysian's gifted students. Those behaviors are having a variety of interests, unusual curiosity, and persistence in attacking difficult mental tasks, creativity or divergent thinking, leadership qualities, above average language development, unusual emotional depth and intensity, heightened sensitivity, and a sense of justice. This information conveys that the educational system should be responsive to these needs. Teaching in the classroom is no longer a process of transmitting information from teachers to students. Students need to be given the opportunity and guidance to explore their interests and curiosity. In addition, teachers need to give students room to think divergently and be creative in their work. On the other hand, teachers should accept students who exhibit heightened sensitivity or unusual emotional depth and intensity regarding some events. This is because gifted students are capable of understanding many situations but may not be equally capable of handling their emotions. Nevertheless, behaviors of the academically talented students need to be studied, in an effort to understand them.

\subsection{Profiles of Gifted Students}

Bets and Neihart (1988) grouped the profiles of gifted and talented students into six categories. Teachers could easily identify gifted students who belong to the first group. They are creative, autonomous and self-directed in their academic pursuits. These students usually succeed with excellence in school-related activities. The second type of profile is regarded as challenging. They are non-conformers but are autonomous and independent. They often feel frustrated and helpless with the school system. It can be debilitating when they are not equipped with the necessary skills to match the school system that demands a certain standard of behavior. Students are expected to adhere to rules and regulations. Parents and teachers may not realize students' talents. Thus, they neither get the appreciation nor the support. Situations may lead them to misbehave by defying schools rules and regulations.

The third type of gifted students specified by Bets and Neihart (1988) is the underground. These students try to conceal their abilities because they do not feel confident about acting spontaneously. The schools' environments do not encourage the development of gifted and talented behaviors. These students refuse to be regarded as different, and they want to be accepted by their peers. Among the gifted students, there are also those who have dropped out of the school system. This fourth type of gifted students failed to receive the necessary guidance and support from the school system. There is also a category of gifted students who belong to a special population of students with disabilities and special needs. This fifth type of gifted students is sometimes referred to as students with dual exceptionalities. The sixth type of gifted students is referred to as autonomous learners, who have the right attitude, the right skills, and the right understanding to pursue life-long learning.

Policymakers in the educational systems should realize that if they fail to respond to the special needs of the gifted and talented students, many of these students inevitably will become underachievers. Carper (2002) researched talented students who had dropped out of the school system. He found that all students involved in the research felt bored with the classroom lessons. Thus, educators need to be aware of the existence and the needs of gifted students in the schools. Studies carried out by Bets and Neihart (1988), and Carper (2002) had categorized the gifted students and the underachievers, but not much was mentioned about their behavioral characteristics. Behaviors are observable and would assist teachers to be aware of their students' educational needs. This is because teachers, school administrators, and parents need to work on enhancing gifted behavioral characteristics among the students. There is a serious need for educators to pay considerable attention to nurturing students' potential that is manifested in gifted behavioral characteristics.

This study was carried out to determine profiles of behavioral characteristics of a group of academically talented 
students in a secondary day school in Malaysia. Gifted education is new in Malaysia, and there is no explicit gifted education provision for the students. The findings would guide researchers and practitioners to a better understanding of academically talented students. The findings would be an impetus for further research in this area and could establish a profile for a bigger population. Understanding academically talented students' characteristics would lead to better and more effective educational interventions and support for gifted students in schools.

\section{Methodology}

This is a multiple case study research that examined the prototypes of behavioral characteristics of academically talented students. The cases referred to were the participants of the study. They were chosen from a day school in the city of Shah Alam. Shah Alam is the capital city of Selangor, one of the states in Malaysia. Although many of these students would be qualified to enroll in any Malaysian boarding school, they chose to remain in their day schools.

\subsection{Participants of the Study}

A non-random, selective sampling procedure was carried out to include 33 students who had obtained grade "A" in all academic subjects in the national standardized examination (refer to Table 1). Students must take this examination (Penilaian Menengah Rendah - PMR or Junior High School Assessment) after completing three years of secondary school. These students were referred to as Academically Talented students (AT) and were chosen from one of the day schools. There were $77(15.13 \%)$ students, from a total of 509 students, who received grade "A" for all subjects (seven or eight subjects) in which they took the PMR examination. According to Piirto (1999) and Renzulli (2001), academically talented students represent the top $15 \%$ of a school population. However, many of these students had been accepted to enroll in boarding schools and junior science colleges throughout Malaysia. The age of the participants of this study ranged from 15 to 16 years old. The 15-year-old participants had been accelerated from standard two (second year of schooling for 8-year-old students) to standard four (fourth year of schooling for 10-year-old students), skipping standard three (third year of schooling for 9-year-old students).

Table 1. Academically talented students who participate in the study

\begin{tabular}{lll}
\hline Race & Gender & Numbers \\
\hline Malay & Girls & 13 \\
& Boys & 4 \\
Chinese & Girls & 3 \\
& Boys & 4 \\
Indian & Girls & 4 \\
& Boys & 3 \\
Mixed & & \\
(Indian + Chinese) & Girl & 1 \\
(Malay + Chinese) & Boy & 1 \\
Total & & 33 \\
\hline
\end{tabular}

\subsection{Procedure and Instrumentation}

Renzulli's Scale for Rating the Behavioral Characteristics of Superior Students (SRBCSS) was adapted for use by Malaysian teachers. This instrument rates students in ten different behavioral characteristics: Learning, Creativity, Motivation, Musical, Planning, Artistic, Expressive Communication, Receptive Communication, Leadership, and Dramatics. The statements in the rating scale were translated into Bahasa Malaysia, and the original English statements were kept. This was to facilitate use by bilingual teachers who used the scale to rate their students. Thus, keeping the statements written in English had allowed those teachers to do better rating on the students. Each statement describing the behavior was rated from one to six ("always" seen). Two teachers who had taught the academically talented students for one school year rated them on their behavioral characteristics. The inter-rater reliability of the adapted instrument was $.53(\mathrm{n}=64)$ at .01 two-tail significance level. The internal consistency measured was also within the acceptable range $(\alpha=.90, \mathrm{n}=33)$. The effect size and the power for the test of the instrument used are as shown in Table 2. 
Table 2. Effect size, power of test, and suggested sample size for SRBCSS malay version

\begin{tabular}{llll}
\hline Behavioral Characteristics & Effect Size & Power of Test & Suggested Sample Size \\
\hline Learning & .8 & 1 & - \\
Communication & .9 & 1 & - \\
Planning & .7 & 1 & - \\
Motivation & .6 & .87 & - \\
Leadership & .6 & .87 & - \\
Expressive & .4 & .54 & 35 \\
Creativity & .5 & .74 & 40
\end{tabular}

2.3 Data Analysis

The ratings of the two teachers were averaged before any further analysis was conducted. The data obtained were analyzed to identify the latent profile of the behavioral characteristics of academically talented students. Ding (2001) suggested a model that can be used to analyze data in order to see its latent profile. The model suggested is known as Profile Analysis via Multidimensional Scaling (PAMS). This model does not specify the number of participants to be included in the study. A latent profile is that of a prototypical person. A prototypical person describes a person according to the variables studied in a continuous manner. This is different from cluster analysis, which classifies variables into several categories. Thus, a cluster analysis allows one to describe an individual according to different categories. On the other hand, PAMS allows a researcher to look for a prototypical person described by continuous variables that are being analyzed. Two types of prototypes were established for the analysis of this study.

\subsection{Results}

Students' academic backgrounds (Table 3) were analyzed to identify their achievement pattern. At the end of the sixth year of study in a primary school, students must take a national examination. This examination is known as Ujian Penilaian Sekolah Rendah (UPSR) or Primary School Assessment. Students attending national primary school took the assessment test for five subjects. The subjects included 1) Malay language writing test, 2) Malay language comprehension test, 3) English, 4) mathematics, and 5) science. Students attending vernacular schools, such as Chinese Primary Schools (CPS) or Tamil Primary School (TPS), had to take a test for two additional subjects in the UPSR examination. CPS students had to take a Mandarin writing test and a Mandarin comprehension test. On the other hand, students attending TPS had to take a Tamil writing test and a Tamil comprehension test. There were two students who had attended Chinese Primary School and one student who had attended Tamil Primary School who were included in this study.

Table 3. AT students' academic background

\begin{tabular}{llccl}
\hline Race & Gender & UPSR Result & Count & Additional Information \\
\hline Malay & Male & 5A & 1 & Accelerated \\
& & $5 \mathrm{~A}$ & 1 & \\
& & $4 \mathrm{~A} 1 \mathrm{~B}$ & 1 & Accelerated \\
& & $4 \mathrm{~A} 1 \mathrm{~B}$ & 1 & \\
& Female & $5 \mathrm{~A}$ & 4 & \\
& Female & $5 \mathrm{~A}$ & 1 & Accelerated \\
& Female & $4 \mathrm{~A} 1 \mathrm{~B}$ & 5 & \\
& Female & $4 \mathrm{~A} 1 \mathrm{D}$ & 1 & \\
& Female & 3A 2B & 2 & \\
& Male & 7A & 1 & From CPS \\
& Male & $5 \mathrm{~A}$ & 3 & \\
& Female & FA 2B & 1 & From CPS \\
& Female & FA 1B & 1 & \\
& Female & $3 \mathrm{~A} 2 \mathrm{~B}$ & 1 &
\end{tabular}




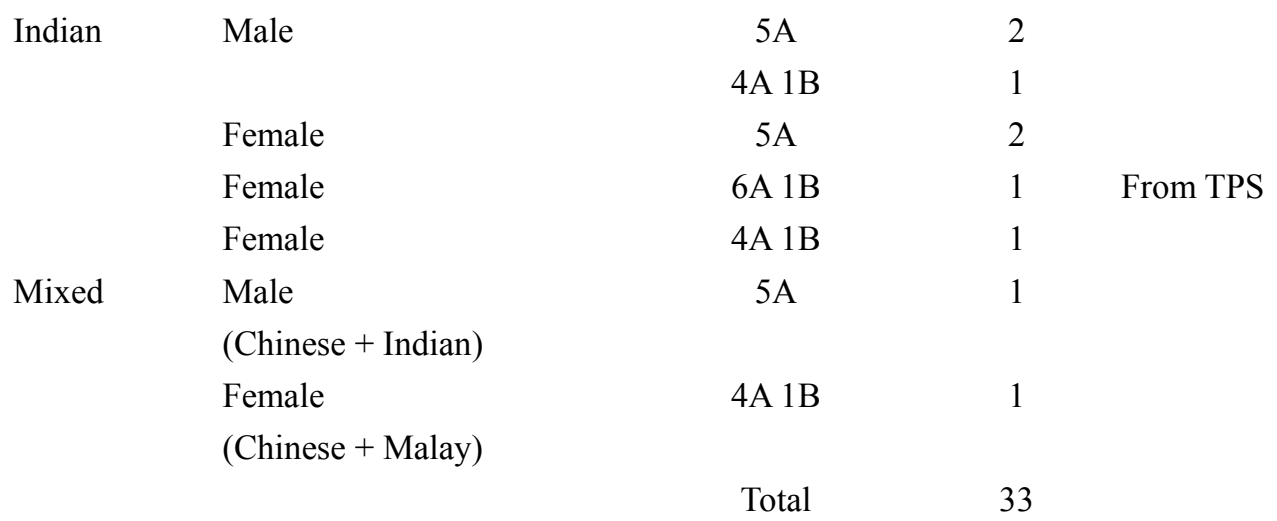

Key: CPS - Chinese Primary School; TPS - Tamil Primary School

Three out of 33 students were accelerated to year five upon passing a special examination in year three. One male (Malay) and one female (Malay) who were accelerated received an "A" for all subjects in which they were tested in the UPSR examination. The other male (Malay), who was accelerated, received four "A's" and one "B" on the same examination. However, the Ministry of Education had already ceased giving a qualifying examination for acceleration and terminated the acceleration program. Sixteen students $(48.5 \%)$ received a grade of "A" for all subjects (five or 7 subjects) sat for in the UPSR examination. Minimal UPSR achievement among these academically talented students was obtaining 3A's" and two "B's." One Chinese girl and two Malay girls achieved this result.

The MDS analysis gives two-dimensional values for ten behavioral characteristics of academically talented students (Table 4, and Figure 1). Those dimensional values were plotted against the ten behavioral characteristics rated by the teachers. Dimension 1 represented Prototype 1 of AT students, and Dimension 2 represented Prototype 2 of AT students. The two lines on the graph represent the two prototypes of academically talented students, as far as their behavioral characteristics were concerned. The first prototype (Prototype 1) demonstrated high ratings in Dramatic, Artistic, and Musical characteristics, and low ratings in Expressive Communication, Precision Communication, Leadership, Motivation, Learning, Creativity, and Planning characteristics. The second prototype (Prototype 2) showed high ratings in Expressive Communication, Precision Communication, Leadership, Motivation, Learning, Creativity, and Planning characteristics, and low ratings in Dramatic, Artistic, and Musical characteristics.

Table 4. Estimated 2-dimensional scales values for 2-prototypes of at students within ten behavioral characteristics

\begin{tabular}{lcc}
\hline & Dimension 1 & Dimension 2 \\
\hline Dramatic & 1.64 & 0.72 \\
Expressive & 0.13 & 0.62 \\
Leadership & -0.97 & -0.17 \\
Artistic & 1.57 & 0.43 \\
Precision & -0.77 & 0.07 \\
Creativity & -0.23 & 0.1 \\
Motivation & -1.45 & -0.33 \\
Musical & 2.37 & -1.26 \\
Learning & -1.32 & 0.01 \\
Planning & -0.97 & -0.19
\end{tabular}




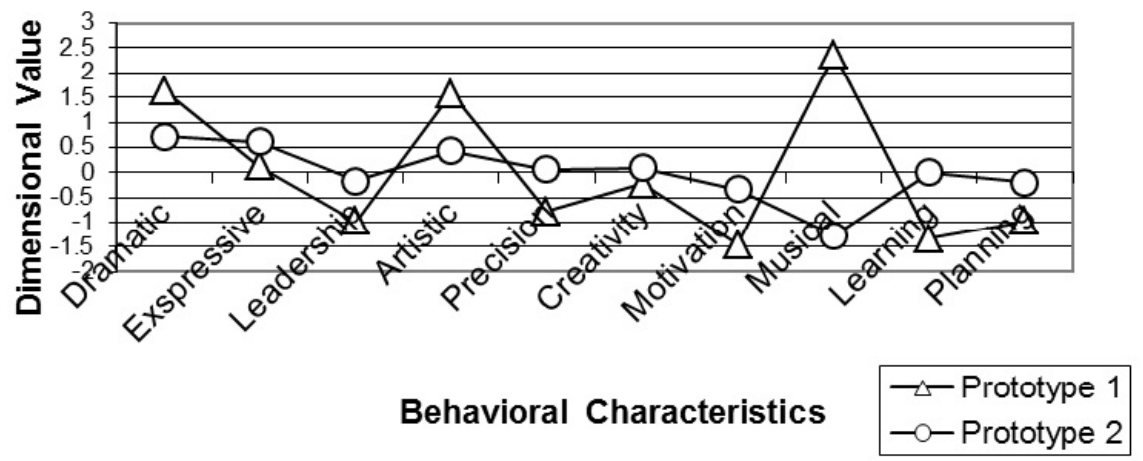

Figure 1. Two behavioral characteristics prototypes for academically talented students

\section{Discussion and Educational Implications}

Analysis of students' academic backgrounds indicated that only 16 students (48.5\%) had a consistent pattern of academic achievement. They managed to receive an "A" in all subjects in which they were tested in both the UPSR and PMR examinations. This left 17 students (51.5\%) who were not performing up to their abilities or underachieved in the UPSR examination. An inconsistent achievement pattern throughout the years suggested the need for serious attention from educators and parents. According to Fatanah (1997), high achievers are those students who are intelligent, have a strong personality, and are responsible and well-disciplined. Thus, students who underachieved might not possess those characteristics. Grant (2001) listed factors that effect students to be excellent in their academic performance. Those factors include proud of previous achievement; receive emotional support for their effort; always expecting success; demonstrating flexible thinking, and not feeling satisfied with average achievement that could lead to the demoralization phenomenon, which should be prevented. Thus, educators must explore students' educational needs and plan educational strategies to respond to those needs. In addition, educators must nurture students' strengths so as to assist students in developing their talents and their fullest potential.

Behaviorally, academically talented students could be categorized into two types: Prototype 1 and Prototype 2 . The first type of academically talented students (Prototype 1) was rated high on Dramatic, Musical, and Artistic characteristics. On the other hand, the teachers rated their behavioral characteristics of Planning, Learning, Motivation, Leadership, and Communication low. This set of students must be helped to nurture those behaviors that were rated low to ensure a well-balanced development. This type of student needs appropriate educational programs, such as leadership training as well as learning skills training. Problem-based learning (PBL) is considered one of the suitable curricula for this type of student. PBL will enhance leadership, planning, motivation, and communication skills among the Prototype I students. Learning and teaching will be much more fruitful if it is conducted in a dramatic, musical, and artistic mode. Using these strategies will enhance gifted students' strengths and achievements, thus preventing underachievement.

The second type (Prototype 2) was rated high on the following behavioral characteristics: Planning, Learning, Motivation, Leadership, and Communication. Nevertheless, their behavioral characteristics in the Dramatic, Musical, and Artistic domains were rated low. This set of students might also be experiencing unbalanced behavioral or skills development, as is the case with the first group of students (Prototype 1). Educators need to plan suitable educational interventions to address this discrepancy. Even though there are co-curricular activities in the schools, including drama, artistic and musical activities, they do not seem to have much effect on academically talented students' skills in those areas. Some of the behavioral characteristics or skills associated with drama, artistic and musical activities could enhance better development of human potential. One behavioral characteristic in the Dramatic category assesses students' ability to "command and hold the attention of a group when speaking." Academically talented students need to have this skill so that they are able to communicate to the public effectively, relaying to the public their in-depth understanding about certain academic matters. Other Dramatic characteristics or skills include the ability to "easily tell a story or give an account of some experience." This skill is important, as it could help students reflect on their experience, thus making it meaningful and enhancing the students' social-emotional adjustment. In other words, this dramatic skill could assist in developing suitable affective or emotional maturity among students. Emotional strength is considered as necessary and very important in talent development (Piirto, 1999).

Prototype 1 students must be helped to improve in their communication skills. Among other things, they must improve in their ability to "speak and write directly and to the point," "explain things precisely and clearly", 
"express thoughts and needs clearly and concisely", "uses voice expressively to convey or enhance meaning" and "use colorful and imaginative figures of speech such as puns and analogies." Teachers must be aware of specific behavioral characteristics that need to be nurtured among students. This will guide teachers to be more focused in their interventions. The interventions may be carried out formally during various sessions in structured programs. Interventions can also be carried out informally during teacher-student interactions that happen in schools. The nurturance that teachers give to their students is not limited to academically talented students only; it is for all students. However, if teachers are not focused in this nurturance or intervention, the education system may fail to realize students' potential to be academically talented at a particular educational level.

There are academically talented (AT) students who need to improve on their planning, learning, motivation, leadership, and communicative behavioral characteristics. Those behaviors are important for sustaining their achievement in academic performance as well as in non-academic performance. Among the behavioral skills listed in the Planning characteristics include the skill to "determine what information or resources necessary for accomplishing a task." This skill is important in accomplishing either academic tasks or non-academic tasks. Other behavioral characteristics of equal importance include the skill to "grasp the relationship of individual steps to a whole process," "allow time to execute all steps involved in a process," "foresee consequences or effects of action," and "organize his or her work well, and see alternative ways to distribute work or assign people to accomplish a task". Rosadah et.al (2011) had found that academically talented students fare very well in project based learning. This kind of learning and teaching approach would enhance students' planning, leadership, and communication skills.

Having certain musical skills can help a student emotionally heal herself through listening to melodies, which are therapeutic in nature (Brandalise, 2004). This Musical characteristic describes a student as a person who "easily remembers melodies and can produce them accurately." The Artistic characteristic sees students who are "particularly sensitive to the environment: keen observers-see the unusual, what may be overlooked by others." This behavioral characteristic such as being a keen observer and having a good memory should also be characteristics of scientists. Scientists used to be academically talented students in schools (Piirto, 1999). Baum et.al (1995) list teachers' behaviors that are crucial for reversing underachievement; these include (1) taking time to get to know the student, (2) focusing on positive traits of the student, (3) understanding their role as facilitator, (4) applying the role of teacher as researcher, and (5) conveying a belief in the students' abilities. Thus, it is very important that teachers pay serious attention to putting sincere effort to behave as such.

\section{Conclusions and Recommendations}

The findings of this study lead us to understand variations within 16-year-old academically talented students at the selected site, a secondary school in Malaysia. Educators need to be aware of these variations, accepting the diversity and helping to nurture and develop students' abilities to the fullest. The first type of student was musically and artistically inclined. These students also exhibited a high score in dramatic behavior. This showed that academically talented students could also be very much inclined towards music, art, and drama at the same time. The second type of academically talented student exhibited behavioral characteristics as expected and typical of gifted students' behavior: high in planning, motivation, learning, leadership, expressive language, and creativity.

This study must be replicated to include more samples from different groups. They could be from schools at other states in Malaysia and also from different types of schools, including primary schools, vernacular schools (Chinese and Tamil), Religious (Islamic) schools, boarding schools, and private schools. It would be of interest to learn if the same pattern of profiles and prototypes would emerge from the study. Data would be analyzed to obtain results for age groups other than the 15 -year-old students in this study.

Developing students' skills and behaviors related to academic performance alone, such as in Planning, Learning, Motivation, Leadership, and Communication is not sufficient. Students need to develop supplementary behavioral characteristics, such as Dramatic, Musical, and Artistic ones. These behavioral characteristics may work as a catalyst to enhance academic performance. Teachers and parents must mold certain behavioral characteristics among the students for a balanced development. Afida et.al (2012) affirmed the enhancement of creativity via experiential learning. Creativity and task commitment are variables that are not permanent. Encouraging suitable practices can develop both behaviors. Both these behaviors enhance each other. A task that calls for creativity demands full commitment from the doer. Thus, parents and teachers should be open-minded and flexible about students' quest for creative encounters in science, arts, music, or drama. Teachers can use drama as one of the curriculum delivery methods. Developing notes by mind-mapping methods is flexible, and 
when students are allowed to draw and use colors for the mind-mapping notes, students are being artistic. Adults need to support and guide children in their creative endeavor. Besides, adults should be cautious not to hinder children from being flexible and divergent in their thought. In addition, parents and teachers need to be serious and focus in enhancing students' behavioral characteristics that are traditionally associated with academic development, such as learning, motivation, communication, and planning. On the other hand, failure to make the necessary interventions could lead to underachievement.

This study showed that students exhibited behaviors across many domains or aspects of talented or gifted characteristics. Teachers must understand students' diverse learning needs so as to better manage teaching and learning activities. Thus, the educational system needs a clear, sound policy for identification of gifted and talented students. The policy also must address educational provisions for the gifted. Consequently, this would lead to the need for teachers' training in the field of gifted education.

\section{References}

Ayob, A., Majid, R. A., Hussain, A., \& Mustaffa, M. M. (2012). Creativity enhancement through experiential learning. Advances in Natural and Applied Science, 6(2), 94-99.

Bets, G., \& Neihart, M. (1988). Profiles of the gifted. Gifted Child Quarterly, 32, 248-253. http://dx.doi.org/10.1177/001698628803200202

Brandalise, A. (2004). Music Therapy: The Use of Music for Healing. Voices: A World Forum for Music Therapy. Retrieved April 14, 2004, from http://www.voices.no/mainissues/mi40004000137.html

Carper, A. B. (2002). Bright students in a wasteland: The at-risk gifted. A qualitative study of fourteen gifted dropouts. Ph.D. Thesis, North Carolina State University.

Clarck, B. (1997). Growing up Gifted. Ed. ke-5. New Jersey: Prentice Hall.

Ding, C. S. (2001). Profile Analysis: Multidimensional Approach. Practical Assessment, Research \& Evaluation, $7(16)$.

Grant, L. C. (2001). Factors positively influencing academically successful, highly motivated African-American high school students. Ph.D. Thesis, Florida International University.

Gross, M. U. M. (1993). Exceptionally gifted children. London: Routledge. http://dx.doi.org/10.4324/9780203315378

Jackson, E. B. (2002). The impact of parenting styles on adolescent academic achievement and classroom behavior. Ph.D. Thesis, Capella University.

Kaur, I. (2002). Merits of General Observation as a Strengthening Measures in Identifying Gifted Students. VirTEC Journal. Retrieved from http://jurnal.myvirtec.net/aindex

Majid, R. A., Yassin, S. F. M., Abdullah, N. G., Ramli, R., Hassan, S. A., Latiff, M. N. B., \& Ishak, N. M. (2011). Project-Based Learning for Academically Talented Students at a Math and Science Camp. World Applied Sciences Journal, 14, 1-5.

Mohamed, F. (1997). Relationship between academic achievement and personality and family factors among MRSM students. Ph.D. Thesis Universiti Kebangsaan Malaysia.

Piirto, J. (1999). Talented children and adults; their development and education (2nd ed.). Ohio: Merrill Prentice Hall.

Renzulli, J. S. (1991). The school wide enrichment model: A comprehensive plan for the development of creative productivity. In Colangelo, N., \& Davis, G. A. (Eds.), Handbook of gifted education. Massachusetts: Allyn \& Bacon.

Renzulli, J. S. (2002). A practical system for identifying gifted and talented students. In Renzulli, J. S., Smith, L. H., White, A. 1., Callahan, C. M., Hartman, R. K.,\& Westberg, K. L. (Eds.), Scales for rating the behavioral characteristics of superior students: Revised edition. Technical and Administration Manual (pp. 46-54). Mansfield Center: Creative Learning Press.

Renzulli, J. S., Smith, L. H., White, A. 1., Callahan, C. M., Hartman, R. K., \& Westberg, K. L. (2002). Scales for rating the behavioral characteristics of superior students: Revised edition. Technical and Administration Manual. Mansfield Center: Creative Learning Press.

Woolfolk, A. E. (1998). Educational psychology (7th ed.). Boston: Allyn and Bacon. 